\title{
The nature, extent, and ecological implications of marine light pollution
}

\author{
Thomas W Davies*, James P Duffy, Jon Bennie, and Kevin J Gaston
}

Despite centuries of use, artificial light at night has only recently been recognized as a cause for environmental concern. Its global extent and ongoing encroachment into naturally lit ecosystems has sparked scientific interest into the many ways in which it may negatively affect human health, societal attitudes, scientific endeavors, and biological processes. Yet, perhaps because sources of artificial light are largely land based, the potential for artificial light pollution to interfere with the biology of the ocean has not been explored in any detail. There is little information on how light pollution affects those species, behaviors, and interactions that are informed by the intensity, spectra, and periodicity of natural nighttime light in marine ecosystems. Here, we provide an overview of the extent of marine light pollution, discuss how it changes the physical environment, and explore its potential role in shaping marine ecosystems.

Front Ecol Environ 2014; 12(6): 347-355, doi:10.1890/130281

$\mathrm{A}^{\mathrm{r}}$ ificial light at night is globally widespread (Cinzano et al. 2001), rapidly expanding in spatial extent (Hölker et al. 2010), and shifting in its spectral characteristics (Davies et al. 2013a). Increasing concern over these trends has recently fuelled a surge in research toward understanding the ecological impacts of artificial light pollution (eg Davies et al. 2012, 2013a; Stone et al. 2012; Dominoni et al. 2013). While the impacts of light pollution are increasingly well documented in terrestrial ecosystems, marine habitats have received comparatively little attention (Depledge et al. 2010). Indeed, in a recent survey in which 592 coastal scientists were asked to prioritize global coastal research questions, artificial light was not included (Rudd and Lawton 2013). Yet, worldwide, more than a billion people ( $23 \%$ of the global population) live within $100 \mathrm{~km}$ of a coastline (Small and Nicholls 2003), and many coastal marine ecosystems are exposed to artificial light at night. Here, we draw attention to artificial light as an environmental issue in marine

\section{In a nutshell:}

- Artificial light pollution is globally widespread in marine environments, altering the natural colors, cycles, and intensities of nighttime light, each of which guide a variety of biological processes

- Known and potential impacts include those on navigation, reproduction and recruitment, predator-prey interactions, and communication in a myriad of marine species and ecosystems, including some of the world's most biologically diverse and functionally important

- Research into these impacts is needed to inform conservation strategies and policy decisions relevant to the holistic management of marine ecosystems experiencing an increasingly diverse array of anthropogenic stressors

Environment and Sustainability Institute, University of Exeter, Cornwall, UK*(thomas.davies@exeter.ac.uk) systems, document its current spatial extent, and highlight a wide array of known and potential ecological impacts.

\section{Nature and extent}

Satellite images of the Earth's nighttime lights are a testimony to humankind's widespread colonization and subsequent influence on the planet's ecosystems (Figure 1). As an initial estimate, in $2010,354760 \mathrm{~km}(22.2 \%)$ of the world's coastlines (excluding Antarctica) were exposed to nightly artificial light pollution (see Table 1 for details). While it might be expected that the coastlines of the developed world are most affected, this is not so: Asia and Africa, for example, have the second and third highest percentage of coastline influenced by light pollution, respectively, with Europe having the highest (Figure 1; Table 1). The amount of artificial light on land is continuing to increase at a rate of $6 \%$ per year globally (Hölker et al. 2010). Given the rapid growth of many developing world economies, future increases are expected to be greater in these regions as compared with the developed world over the coming decades, with unknown consequences for some of the planet's most biodiverse marine ecosystems (Aubrecht et al. 2008).

Sources of artificial light in the marine environment vary, with shipping and light fisheries contributing as temporary sources in nearshore and offshore waters (Figure 2, a and f). Offshore oil platforms and land-based developments such as towns, cities, and their harbors provide more permanent sources that can increase nighttime light intensities across large geographical areas such as estuaries, bays, and continental shelf seas (Figure 2, b and e). Scattering of upwardly emitted or reflected artificial light in the atmosphere and reflection by clouds (artificial skyglow) further extends the spatial influence of landbased light sources (Kyba et al. 2011) into offshore waters, 


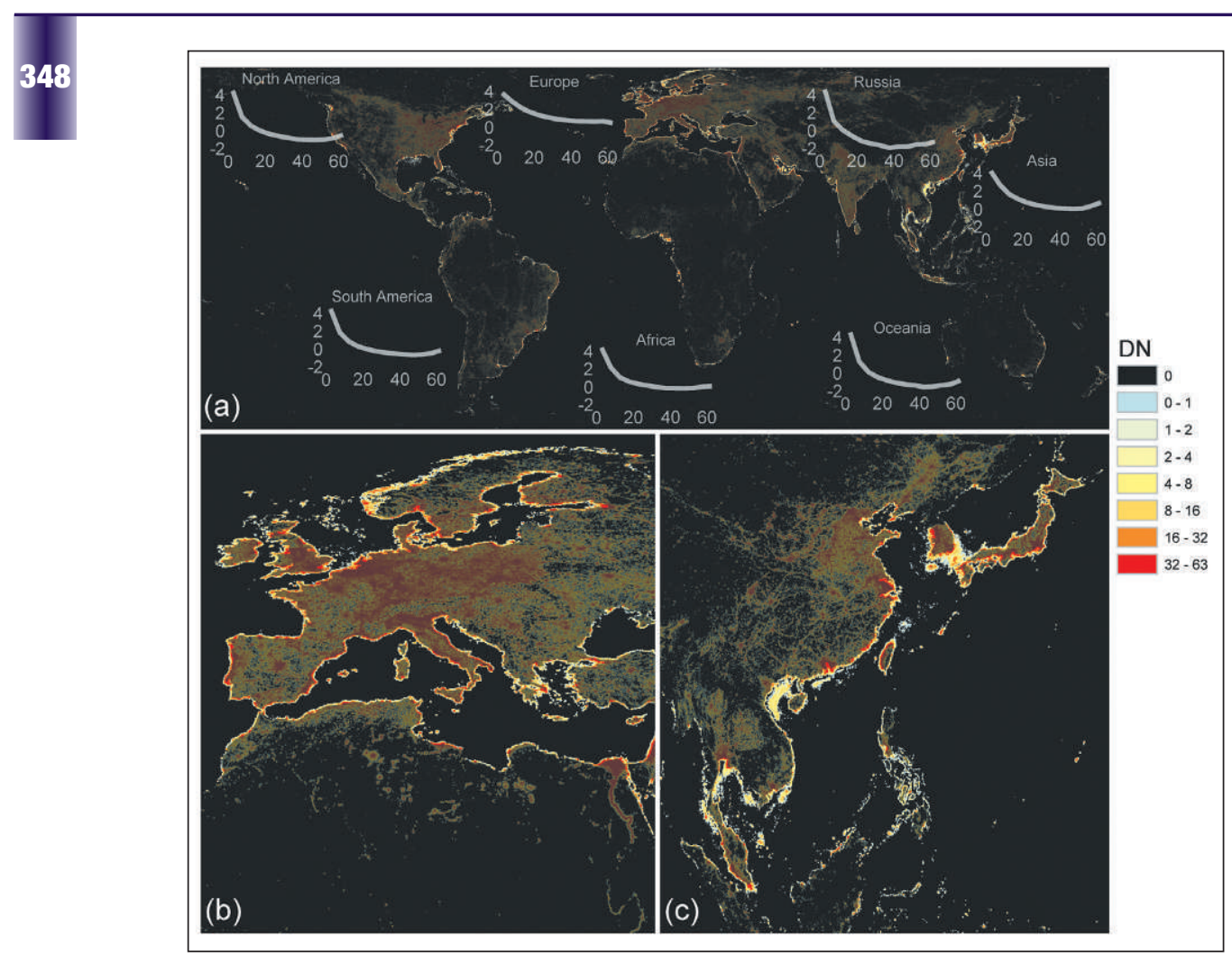

Figure 1. The global extent of marine light pollution. Images are derived from the Defense Meteorological Satellite Program Operational Line Scan nighttime lights image for 2010 (Behrmann equal-area projected; pixels aggregated to 8-km resolution). Graph inserts in (a) represent the distribution of artificial light intensity across continental coastlines, calculated from raw data at the original $\sim 800-m$ resolution. The $x$ axes represent artificial light intensity (0-63 Digital Number [DN]), where the brightest pixels are assigned the highest values); the $y$ axes represent log $\mathrm{km}$ of coastline affected by that intensity of light. Coastlines (highlighted) were defined as anywhere up to $10-\mathrm{km}$ inland.

lightscapes at night (Figure 2c), which were previously lit only by the comparatively constant broad spectrum of moonlight (Figure 2d). This is particularly pertinent to depthdependent biological processes that can be guided by the spectrum of light as it changes through the water column. Blue artificial light will penetrate deeper in the open ocean due to the faster attenuation of red light, increasing its potential scale of influence. Higher concentrations of biological and nonbiological particulates alter this attenuation so that, for instance, green artificial lights would penetrate deepest in temperate regions where phytoplankton absorb other wavelengths.

Given the increasing proportion of coastlines that are artificially illuminated and the variety of ways this alters the natural light regimes with which marine organisms have evolved, it is essential that scientists gain a better understanding of the known and potential ecological consequences of artificial light in marine ecosystems.

\section{Ecological implications}

The vast majority of species have and masks natural rhythms of lunar light intensity (Davies et al. 2013b) that provide information for regulating a number of biological processes in the ocean (Naylor 1999). Ongoing shifts in prevailing technologies are resulting in an increasing use of "white" or broader spectrum lights (Gaston et al. 2012), and a greater variety of spectrally distinct lighting types is creating complex spatial patterns of color and brightness across marine

Table 1. The spatial extent of coastal light pollution

\begin{tabular}{lcc}
\hline Region & $\begin{array}{c}\text { Kilometers of } \\
\text { coastline affected }\end{array}$ & $\begin{array}{c}\text { Percent of } \\
\text { coastline affected }\end{array}$ \\
\hline Europe & 115383 & 54.3 \\
Asia (excluding Russia) & $1 / 3166$ & 34.2 \\
Africa & 18589 & 22.1 \\
South America & 24197 & 15.5 \\
North America & 64356 & 11.8 \\
Oceania & II 692 & 7.9 \\
Russia & 7377 & 6.1 \\
Total & 354760 & 22.2 \\
Notes: Values are derived from a Behrmann equal-area projected Defense & \\
Meteorological Satellite Program Operational Line Scan nighttime lights image \\
from 20I0 (see Figure I). Light-polluted areas of coastline were defined as those \\
where the pixel intensity was greater than five on an uncalibrated scale between \\
zero and 63. Antarctica was omitted when calculating the total \% of coastline. \\
\hline
\end{tabular}

evolved under natural and predictable regimes of moonlight, sunlight, and starlight. These regimes define species' activity times (eg nocturnal, crepuscular, diurnal), offer a useful navigational aid, help to regulate and coordinate maturation and reproductive events, and provide a relatively constant irradiance spectrum that can regulate physiology and inform visually guided behaviors such as predation and communication (Gaston et al. 2013). Many of these processes are affected by artificial nighttime light in terrestrial ecosystems: for example, in birds, sexual maturation is advanced (Dominoni et al. 2013), foraging effort is intensified (Titulaer et al. 2012), and the timing of dawn song is extended into the night (Nordt and Klenke 2013). Some species are attracted to artificially lit areas where they may experience increased predation (Rydell 1992), while others avoid artificially lit areas (Stone et al. 2012), and so are displaced from habitats that would otherwise be suitably dark in the absence of artificial lighting. Many of the same types of light cues are just as intrinsic to the ecology of marine species as they are for terrestrial species. Artificial nighttime light is therefore likely to affect a diverse array of ecological processes in the marine environment (Figure 3). Here, we highlight some of the major impacts, providing examples 
from taxa known to be affected as well as functionally important taxa that are likely to be affected.

\section{Orientation}

Perhaps the best-known impact of artificial light is the disorientation experienced by species that use natural light cues to navigate, most notably birds and sea turtles (Tuxbury and Salmon 2005; Merkel 2010) in marine systems. Bird strikes, involving a variety of species, on artificially lit vessels at sea are common at night (Merkel 2010), whereas coastal lighting disorientates turtle hatchlings and prevents or delays them from locating the sea (Tuxbury and Salmon 2005), ultimately reducing the number of turtle nesting sites in artificially lit locations (Mazor et al. 2013). In the intertidal environment, moonlight provides a compass for navigation by the invertebrate sandhopper Talitrus saltator (Ugolini et al. 2005), raising the question of whether artificial lighting is disrupting lunarorientated tidal migrations. This behavior is also seen in terrestrial species, such as dung beetles (Dacke et al. 2003), and is likely to be widespread across both terrestrial and marine arthropods. Behavioral responses to artificial light have also been demonstrated in various fish species (Marchesan et al. 2005). For instance, sea cages that are artificially lit affect depth selection in Atlantic salmon (Salmo salar; Oppedal et al. 2011), while coastal lighting around estuaries can aggregate fish in artificially lit habitats (Becker et al. 2012). Indeed, the attraction of the larval stages of many fish species to artificial lights has led to the development of light-based trapping methods that are analogous to those used for trapping nocturnal Lepidoptera (Doherty 1987). Artificial lights are commonly used by the fishing industry to attract and catch several squid species. Those lights are so powerful that nighttime satellite images can be used to quantify fishing pressure, spawning grounds, and migration routes (Figure 2f; Kiyofuji and Saitoh 2004). The geographically widespread use of powerful artificial lights in these fisheries is likely to influence the behavior and survivorship of many nontarget as well as target species over large spatial scales.

Light intensity and spectra are especially useful cues by which organisms regulate their depth in the pelagic environment where landmarks are absent. While some species have evolved the ability to navigate horizontally via detection of the Earth's geomagnetic field, the visible portion of the electromagnetic spectrum is one of the most important means of vertical navigation. Consequently, light intensity informs the vertical movement of zooplankton species that migrate to surface waters at night to graze while avoiding predation (Cohen and Forward 2009). Given that artificial skyglow is more widespread than direct artificial light (Cinzano et al. 2001) and frequently occurs at intensities greater than (and thus directly interferes with) natural lunar sky 


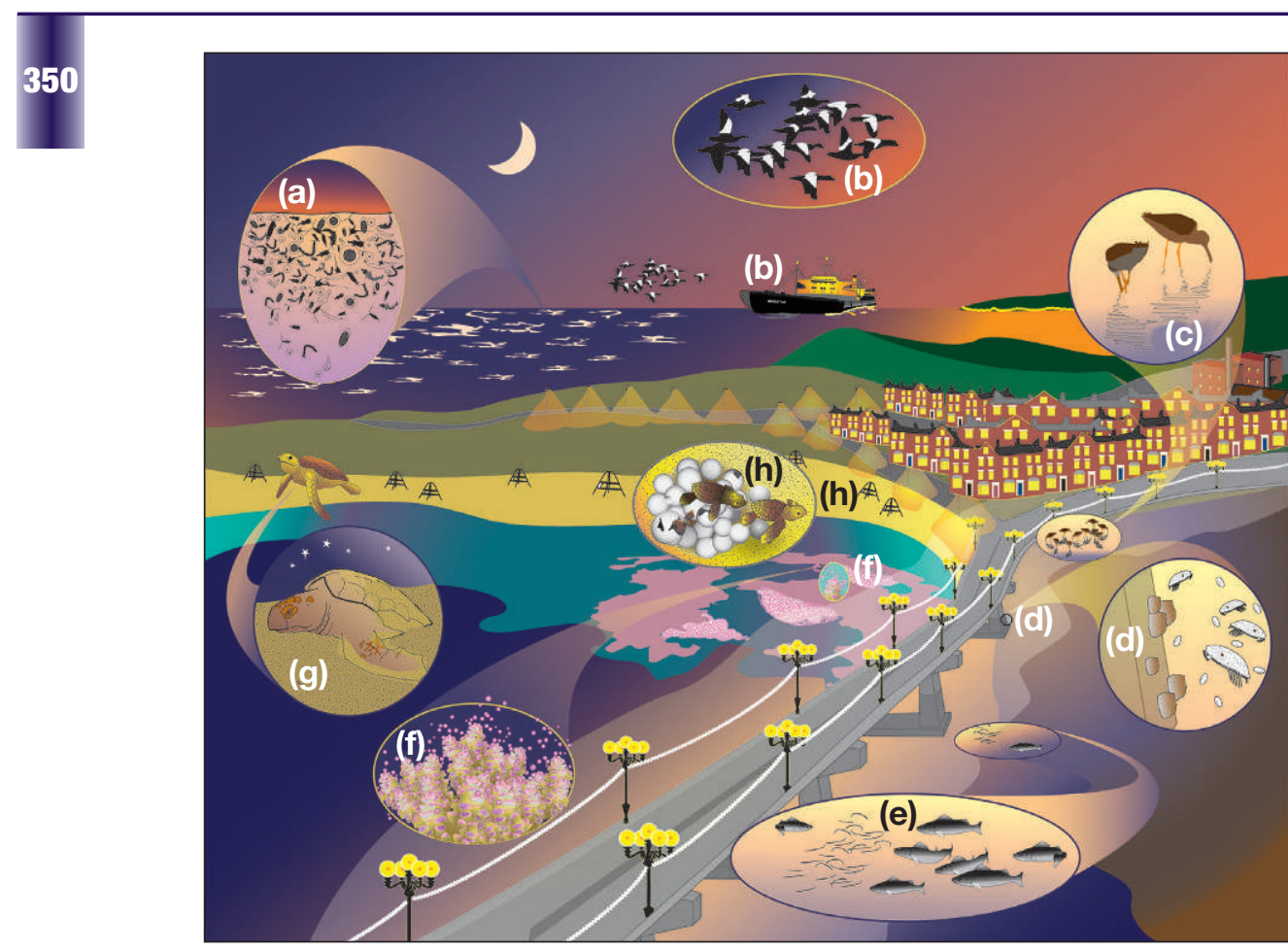

Figure 3. Known and potential impacts of artificial light pollution on marine ecosystems. (a) Suppression of zooplankton diel vertical migration by artificial skyglow. (b) Bird strikes on lit ships at night. (c) Extension of visual foraging behavior in coastal wading birds into the night. (d) Disruption of settlement site selection in sessile invertebrate larvae. (e) Aggregation of fish under pier lights leads to intensified predation. (f) De-synchronization of broadcast spawning from lunar phase (corals releasing gametes). (g) Displacement of nesting sea turtles from artificially lit nesting areas. (h) Disorientation of seaward migration in sea turtle hatchlings by street lights. light regimes to regulate rates of reproductive maturation and synchronize broadcast spawning events (the release of male and female gametes into the surrounding environment). In the aquaculture industry, these photoperiodic responses are manipulated with artificial lighting to control sexual maturation (Oppedal et al. 2011). A classic example of apparent lunar periodicity in broadcast spawning is the palolo worm (Eunice viridis), which releases gametes over a few days of the year during the third-quarter moon in October (Naylor 1999). Other marine polychaetes apparently also synchronize reproductive events to lunar cycles (Bentley et al. 1999), as do some corals (Harrison 2011) and echinoderms (Lessios 1991). The degree to which lunar light intensity alone regulates such events, as compared to the role of variables such as day length, temperature, and tidal conditions, is unknown for many taxa. However, it seems likely that in numerous cases a combination of these cues is used to regulate gamete development, with lunar light intensity providing the final trigger for spawning (Harrison 2011). In addition, it has been postulated that the spectral conbrightness (Davies et al. 2013b), it seems likely that temporal patterns of zooplankton migration will be affected in artificially lit waters. Indeed, artificial light reflected back to Earth from urban areas (a primary source of artificial skyglow) limits the vertical migration of Daphnia spp in freshwater lakes (Moore et al. 2000).

The nightly vertical movement of zooplankton toward the ocean surface is arguably the largest daily migration of biomass on the planet (Hays 2003). The consumption of near-surface phytoplankton by migrating zooplankton during the night and the subsequent defecation of fecal pellets at depth during the day (Hays 2003; Cohen and Forward 2009) constitutes a major pathway in the carbon cycle, and the adaptive behavior of predators to the vertical movements of their prey results in the daily migration of entire food webs (Hays 2003). Artificial light pollution has the potential to disrupt this vertical migration pattern, and with it the productivity and cycling of carbon and nutrients in marine ecosystems.

\section{Reproduction and recruitment}

The movements of the celestial bodies create predictable regimes in the intensity and duration of light that organisms use as a clock to synchronize activity (Naylor 1999). In the marine environment, many species use natural trasts between moonlight and daylight vary more predictably than intensity alone (Sweeney et al. 2011), implying that changes in artificial light spectra, and consequently the colors of skyglow, may also affect broadcast spawning synchronicity. The advantage of synchronizing spawning events is unclear, although it is probably linked to maximizing reproductive contact between conspecifics (Harrison 2011). Lunar light intensity and day length offer two cues that vary predictably and independently of other environmental variables that are influenced by more stochastic Earth-bound processes. This includes tidal height and current velocity, which - in contrast to the single detectable peak of lunar brightness every 29.5 days - have multiple peaks within this time frame that are more spatially variable in magnitude and timing. The "lunar clock" can, however, be masked by artificial skyglow (Davies et al. 2013b), which may interfere with the synchronization of spawning events, resulting in decreased cross fertilization and ultimately a decline in recruitment among broadcast-spawning species.

It is well known that the intensity and spectral characteristics of light inform the orientation and settlement of the larvae of a broad array of sessile invertebrates (Thorson 1964), including corals, arthropods, polychaetes, echinoderms, tunicates, and bryozoans. Altering the intensity or spectral signature of light could interfere 
with both the pelagic and pre-settlement stages of marine invertebrate life cycles, with major consequences for sessile invertebrate ecosystems. For example, as in many shallow seabed communities, coral reef assemblages are structured vertically with increasing depth (Vermeij and Bak 2002). Coral larvae identify their optimum settlement zones using the intensity and spectral characteristics of light (Mundy and Babcock 1998), which vary with depth due to the differential absorption of different wavelengths of light in water. In a similar fashion, light intensities allow the larvae of sessile invertebrates in shallow subtidal environments to avoid settling in areas that are sufficiently lit to facilitate the growth of competitive algal species (Glasby 1999), giving rise to horizontal structuring of ecological communities. Artificial lights alter the spectrum and intensity of light that larvae experience, resulting in suboptimal selection of sites to settle and metamorphose into adult form. For instance, barnacle larvae can choose settlement zones under white light intensities of $1 \times 10^{-5}$ lumen $\mathrm{m}^{-2}$ (lux) (Crisp and Ritz 1973), which is four orders of magnitude less than that emitted by urban skyglow (Gaston et al. 2013). In sessile invertebrates, settlement site selection ultimately decides survival and reproductive success; hence changing natural light regimes could plausibly affect the composition and functioning of these communities, the members of many of which (eg reefs) are ecosystem engineers.

\section{Predation}

A variety of cryptic anti-predator defenses have evolved in the marine environment, of which camouflage and nocturnality are two of the most widespread. The ability to locate prey or avoid a predator depends largely on the predator's ability to recognize its quarry against complex backgrounds of shape, color, and pattern, and the prey's ability to disguise itself to avoid detection (Troscianko et al. 2009). Many species have evolved color patterns to blend in with their environment and nocturnal behaviors to avoid predator contact, while polymorphic color varieties allow some species populations to rapidly adapt to different environments and to predators with contrasting methods of prey search behavior. The increased intensity of artificial light as compared to moonlight, and the broadening of artificial light spectra, provides greater opportunities for predatory species to recognize their prey, potentially allowing diurnal and crepuscular foraging behaviors to encroach further into the night, displacing nocturnal prey or predator species from habitats that were previously exposed only to natural regimes of darkness. Prey species may experience intensified predation pressure, resulting in localized population declines or shifts in the frequency of particular polymorphs toward types that are less conspicuous under artificial night lighting.

Several studies have shown that the attraction of nocturnal Lepidoptera to street lights at night results in aggregations upon which opportunistic bat species often prey

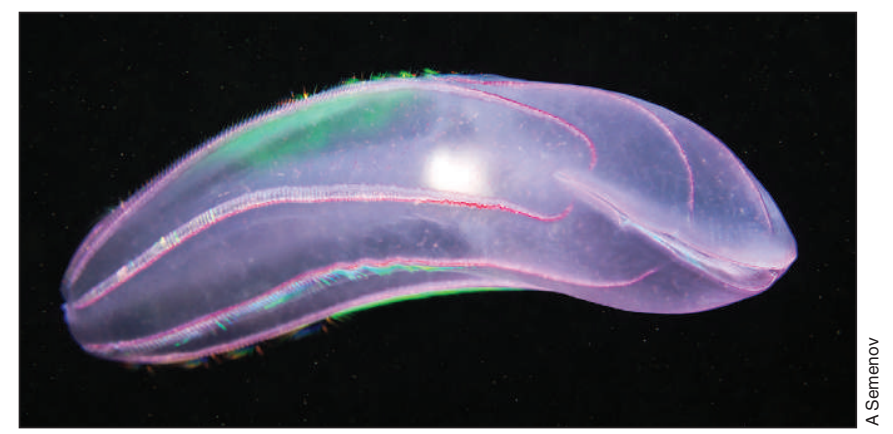

Figure 4. The bioluminescent comb jelly, Beroe cucumis, occurs at depths that can be penetrated by artificial light.

(Rydell 1992). In the marine environment, direct artificial light aggregates both small prey fish and larger predatory species, increasing predation pressure in a similar fashion (Becker et al. 2012). In another example, turning off the lighting on bridges spanning the Puntledge River in British Columbia, Canada, reduced the intensity of predation by harbor seals (Phoca vitulina) on migrating juvenile Pacific salmon (Oncorhynchus spp; Yurk and Trites 2000). Similarly, artificially lit intertidal mud flats allow coastal waders to employ more profitable visually guided foraging behaviors later into the night (Dwyer et al. 2013). Where the distribution of artificial light is patchy, this can result in competition for optimal foraging zones based on artificial light intensity (Dwyer et al. 2013) and intensified predation within more brightly lit patches.

Many marine taxa emit light generated from biochemical reactions (bioluminescence; Figure 4) to avoid predation or to lure prey. Although popular perceptions of bioluminescence are often associated with the deep sea, it is evolutionarily and geographically more widespread throughout the oceans, occurring in fish, tunicates, echinoderms, arthropods, annelids, ribbon worms (Nemertea), cnidarians, mollusks, dinoflagellates, bacteria, and chaetognaths in both oceanic and nearshore environments (Haddock et al. 2010). Anti-predator strategies include using light displays to confuse predators, sacrificing lightemitting body parts to distract predators, attracting the predator's own predators, and mimicking ambient light from above to avoid silhouette detection by predators from below (Haddock et al. 2010). The effects of artificial lighting on these types of interactions are thus far largely unexplored. The narrow spectrum of 590-nanometer (nm) visible light emitted by widely used 20th-century low-pressure sodium lighting technologies and the short-wave spectral peak of $\sim 470 \mathrm{~nm}$ emitted by most bioluminescent marine taxa (Haddock et al. 2010) suggest that in the past, in nearshore environments at least, land-based municipal lighting may have had limited impacts on interactions governed by bioluminescent communication. However, the increasing use of broader spectrum lighting technologies (eg light-emitting diodes [LEDs]) over the coming decades will result in an increasing amount of land-based artificial light illuminating the $470-\mathrm{nm}$ communication channel (Davies et al. 2013a) in inshore waters. 


\section{Communication}

Complex eyes have evolved independently in several marine lineages, including fish, cephalopods, and arthropods, and just as in many terrestrial taxa, the spectra, patterns, and angles of light reflected from individuals are useful elements in inter-and intraspecies communication. As with butterflies and birds, the boldness of colorful markings communicates competitive fitness to potential mates in many marine arthropods (Detto 2007) and fish (Siebeck et al. 2010). Cephalopods use adaptive displays of color and pattern, created by a combination of reflecting and colorchanging cells to communicate (Mäthger et al. 2009); the iridescent markings on squid, for example, vary in appearance depending on the position of the onlooker. This could facilitate communication of shoaling behavior between conspecifics, a type of visual communication that may also be exploited by fish for the same purpose (Mäthger et al. 2009).

The current introduction of artificial lights that emit broader spectra means that visually guided behaviors such as mate selection are more likely to be influenced by light pollution, since many of the physical features that are used to communicate fitness will be more recognizable under whiter lighting (Davies et al. 2013a). This includes the use of lights that emit ultraviolet (UV), a communication channel that some species exploit almost exclusively to avoid predation or to distinguish between closely related species (Siebeck et al. 2010). The Ambon damselfish (Pomacentrus amboinensis), for instance, uses UV light reflected in species-specific patterns to discriminate between conspecifics and other species of damselfish that appear identical at visible wavelengths (Siebeck et al. 2010).

Bioluminescence signals are also used in sexual communication by marine species in a way that is analogous to fireflies (Haddock et al. 2010). Examples include ostracods that attract mates using bioluminescent signals and ponyfishes (Leiognathidae) that use dimorphic bioluminescent displays to differentiate between sexes (Haddock et al. 2010). The potential for artificial lights to disrupt mating behaviors that rely on bioluminescent cues has been raised with fireflies (Longcore and Rich 2004); artificial light could also possibly disrupt such interactions in marine taxa.

\section{Moving forward}

We have drawn attention to artificial light as a threat to marine biodiversity and highlighted some of the diverse array of species, behaviors, interactions, and ecosystems that are likely to be affected. The challenge now is to quantify the extent of the threat posed in regions where such species and ecosystems exist, to develop a sound knowledge base from which to design protective measures, and to identify how such measures can best be implemented. In this section, we highlight some of the key components of such work.

\section{Quantifying threat extent}

Quantifying the extent of the threat posed by light pollution to the ecology of marine systems requires research on the number and phylogenetic breadth of species affected, the spatial influence of artificial light in marine ecosystems, and the range of biological complexity across which impacts occur.

In order to guide this process it is useful to know which species are likely to be vulnerable and whether they are currently or are likely to be exposed to artificial light pollution. Ecologists can identify vulnerable species both by looking for marine analogs of biological responses in terrestrial ecosystems and by extrapolating from studies that document the role of natural light in marine ecosystems. Screening for responses across many taxa can assist in the development of comprehensive lists of vulnerable species or behaviors, but such an approach can also be costly and time-consuming. Targeting research toward species and ecosystems that have obvious ramifications for human well-being (eg biomass production, coastal protection, ecosystem stability, biogeochemical processes) will provide clear economic incentives for developing a thorough understanding of the problem, while remote-sensing tools can be used to identify regions already exposed to and likely to become exposed to light pollution in the future as priority research areas.

Global satellite images of nighttime lighting have proven useful for identifying areas of coral reefs that are exposed to light pollution (Aubrecht et al. 2008), and this approach could be extended to map artificial light in marine protected areas, as well as other regions containing species known to be sensitive to artificial lighting. However, satellite images are limited to measuring light emitted upward, under clear-sky conditions while organisms are exposed to direct and scattered lighting and light reflected back from the atmosphere, the amount of which can vary with local meteorological conditions in space and time. A large-scale spatial and temporal analysis of light pollution trends and long-term biological effects therefore requires a suitable array of ground-based sensors with which to augment and groundtruth satellite data so that accurate predictive models can be developed. Sky Quality Meters (SQMs; Unihedron, Grimsby, Canada) have proven useful for quantifying nighttime sky brightness at ground level in terrestrial systems (Kyba et al. 2011; Davies et al. 2013b); however, only a few SQMs have been deployed in coastal areas and none so far in the open ocean. Offshore infrastructure including oil platforms, "ships of opportunity" (ships willing to participate in long-term monitoring programs), and the Global Ocean Observing System (sea surface buoys) all hold potential for establishing such a network of devices, providing the logistical challenges associated with offshore deployment can be overcome.

Measuring and monitoring marine light pollution at large spatial scales offers the possibility of identifying threatened regions, quantifying trends, and formulating 
predictive models of where future impacts are most likely to occur. Understanding where sensitive species and ecosystems are exposed to artificial light also requires that mapping and modeling take account of vertical as well as horizontal variability in artificial light, so that factors such as turbidity, which determines how spectrum and depth interact to affect intensity, can be quantified.

\section{Developing a sound knowledge base}

As with many emerging ecological issues, research into marine light pollution will initially focus on documenting the range of species, behaviors, and places that are affected. It is also imperative that investigators explore the context of these effects to identify ecologically sound mitigation measures that could provide alternatives to the complete elimination of artificial lighting (as this will not always be possible). For example, many biological responses - including those associated with communication, larval recruitment, or phototactic reactions in mobile fauna - are likely to be spectrally dependent. Narrow-band optical filters and LEDs offer the potential for controlling the intensity and spectrum of artificial light independently, enabling investigators to identify those regions of the light spectrum that have minimal biological impacts. Experiments of this nature can be used as a basis for the development of mitigation strategies, while those that document the impacts of artificial lighting in the environment provide the impetus for doing so.

Long-term databases offer opportunities to quantify the role of light pollution in driving population fluctuations, and to monitor the success of preventative and remedial measures. An example of one such monitoring scheme is the British Antarctic Survey's bird strike log, where bird strikes on ships are digitally recorded. Rolling out such a program across shipping globally would help to identify "hotspots" of human-wildlife conflict, where operational procedures could be put in place to minimize ecological impact. The data generated also offer the capability to identify seasonal and climatic influences on bird strike occurrences, and to evaluate the success of mitigation measures such as switching off deck lighting during non-operational hours and installing lights with narrow emission spectra that reduce bird collision incidents (Secretariat of the Antarctic Treaty 2010; Merkel 2010).

To appreciate the consequences of marine light pollution for the goods and services provided to humanity by marine ecosystems, investigators can focus on whether direct impacts on one species can result in cascading impacts throughout ecological networks. For instance, while there is evidence that artificial light facilitates nocturnal visual foraging in wading birds (Dwyer et al. 2013), it is not known how this affects the macro-infaunal communities on which the birds feed or the ecosystem processes these communities perform. Many of the ecological responses to artificial light discussed here could lead to secondary effects on associated species, trophic structure, and ecosystem functioning, thereby compromising the delivery of ecosystem services. Various long-term ecological field manipulations of light pollution have recently been established in terrestrial systems. By artificially illuminating previously dark habitats at night, these experiments are elucidating the impact of light pollution at the community and ecosystem levels. The intertidal and shallow sublittoral marine environments offer several tractable systems where similar experiments could be performed.

\section{Reducing environmental impacts}

Initiatives to preserve naturally lit landscapes exist through national and international programs that recognize the value of dark skies (eg www.darkskyparks.org). The International Dark-Sky Association's Dark Sky Parks program, The Starlight Foundation's Starlight Reserves, and the UK's Science and Technology Facilities Council's Dark Sky Discovery Sites are all examples of initiatives that award dark sky status to areas where light pollution is minimized. By participating in such programs, local governing authorities are incentivized to adopt measures that preserve natural darkness and the cultural, ecological, aesthetic, and scientific benefits this provides. Although coastal regions have been awarded status under some of the national schemes, expanding these initiatives more widely to include "marine dark sky parks" would be a positive step toward protecting currently dark regions of the marine environment against encroaching light pollution, while capitalizing on benefits to society, the environment, and economic gains through nature tourism.

Artificial light pollution has only recently become widely recognized as an environmental issue. Statutory tools for mitigating against its ecological impacts are therefore largely lacking in marine environments. At present, the International Convention for the Prevention of Pollution from Ships (MARPOL) does not recognize artificial light as a pollutant. Some examples of voluntary mitigation measures have, however, been adopted by individual nations in sensitive areas such as the Antarctic, although these guidelines have yet to be adopted formally by all Antarctic Treaty Committee members (Secretariat of the Antarctic Treaty 2010). Indeed, in many cases it is difficult for policy makers to introduce statutory mitigation measures where these conflict with local economic gains or operational safety issues and there is a limited understanding of the severity of the problem. This is highlighted in the European Commission Marine Strategy Framework Directive (Commission decision 2010/ 477/EU; MFSD 2010). Despite being recognized under Descriptor 11, the Commission did not specify any formal criteria for light, stating that "Additional scientific and technical progress is still required" (MFSD 2010). As a result, standards defining environmentally "acceptable" levels of light pollution in marine waters are unlikely to feature in the corresponding legislative tools drawn up by 
the member nations of the European Union (EU). A concerted research effort is clearly needed to document and understand the environmental impacts of light pollution in the marine environment so that effective statutory protective measures can be developed.

\section{Conclusion}

Artificial light pollution is a global environmental issue, the ecological impacts of which are only now beginning to be examined in detail. Current knowledge of these impacts in marine ecosystems is insufficient to determine the scale of the problem and its likely interactions with other anthropogenic pressures, nor can it inform the implementation of effective protective measures. Yet artificial light at night is potentially damaging to some of the world's most biologically diverse and functionally important marine ecosystems, and as such should be considered a threat to human well-being. In the absence of sound scientific understanding, precautionary measures should be taken to minimize the ecological impacts of light pollution in marine environments wherever possible. Where statutory tools are lacking, introducing voluntary codes of practice and seeking incentives to preserve naturally lit areas through dark skies initiatives should be encouraged as preventative measures. A concerted research drive is needed to inform the design of realistic and effective management strategies that can bring benefits to both ecology and society. The scale of this research landscape is extensive and is truly interdisciplinary, demanding input from terrestrial, freshwater, and marine ecologists; physical oceanographers; remotesensing scientists; and marine engineers.

\section{Acknowledgements}

The research leading to this paper has received funding from the European Research Council (ERC) under the EU's Seventh Framework Program (FP7/2007-2013)/ ERC grant agreement No 268504 to KJG. Our thanks to visual artist $\mathrm{H}$ Guy, who provided equipment and guidance for acquiring some of the images in Figure 2.

\section{References}

Aubrecht C, Elvidge CD, Longcore T, et al. 2008. A global inventory of coral reef stressors based on satellite observed nighttime lights. Geocarto Int 23: 467-79.

Becker A, Whitfield AK, Cowley PD, et al. 2012. Potential effects of artificial light associated with anthropogenic infrastructure on the abundance and foraging behaviour of estuary-associated fishes. J Appl Ecol 50: 43-50.

Bentley MG, Olive PJW, and Last K. 1999. Sexual satellites, moonlight and the nuptial dances of worms: the influence of the moon on the reproduction of marine animals. Earth Moon Planets 85-86: 67-84.

Cinzano P, Falchi F, and Elvidge CD. 2001. The first world atlas of the artificial night sky brightness. Mon Not R Astron Soc 328: 689-707.
Cohen JH and Forward RB. 2009. Zooplankton diel vertical migration - a review of proximate control. Oceanogr Mar Biol 47: $77-110$.

Crisp DJ and Ritz DA. 1973. Responses of cirripede larvae to light. I. Experiments with white light. Mar Biol 23: 327-35.

Dacke M, Nilsson D-E, Scholtz CH, et al. 2003. Animal behaviour: insect orientation to polarized moonlight. Nature 424: 33.

Davies TW, Bennie J, and Gaston KJ. 2012. Street lighting changes the composition of invertebrate communities. Biol Lett 8: 764-67.

Davies TW, Bennie J, Inger R, et al. 2013a. Artificial light pollution: are shifting spectral signatures changing the balance of species interactions? Glob Change Biol 19: 1417-23.

Davies TW, Bennie J, Inger R, and Gaston KJ. 2013b. Artificial light alters natural regimes of night-time sky brightness. Sci Reports 3: 1722.

Depledge MH, Godard-Codding CA, and Bowen RE. 2010. Light pollution in the sea. Mar Pollut Bull 60: 1383-85.

Detto T. 2007. The fiddler crab Uca mjoebergi uses colour vision in mate choice. P Roy Soc B 274: 2785-90.

Doherty PJ. 1987. Light-traps: selective but useful devices for quantifying the distributions and abundances of larval fishes. B Mar Sci 41: 423-31.

Dominoni D, Quetting M, and Partecke J. 2013. Artificial light at night advances avian reproductive physiology. P Roy Soc B 280: 20123017.

Dwyer RG, Bearhop S, Campbell HA, and Bryant DM. 2013. Shedding light on light: benefits of anthropogenic illumination to a nocturnally foraging shorebird. J Anim Ecol 82: 478-85.

Gaston KJ, Bennie J, Davies TW, and Hopkins J. 2013. The ecological impacts of nighttime light pollution: a mechanistic appraisal. Biol Rev 88: 912-27.

Gaston KJ, Davies TW, Bennie J, and Hopkins J. 2012. Reducing the ecological consequences of night-time light pollution: options and developments. J Appl Ecol 49: 1256-66.

Glasby TM. 1999. Effects of shading on subtidal epibiotic assemblages. J Exp Mar Biol Ecol 234: 275-90.

Haddock SHD, Moline MA, and Case JF. 2010. Bioluminescence in the sea. Annu Rev Mar Sci 2: 443-93.

Harrison PL. 2011. Sexual reproduction of scleractinian corals. In: Dubinsky Z and Stambler N (Eds). Coral reefs: an ecosystem in transition. Dordrecht, the Netherlands: Springer.

Hays GC. 2003. A review of the adaptive significance and ecosystem consequences of zooplankton diel vertical migrations. Hydrobiologia 503: 163-70.

Hölker F, Moss T, Griefahn B, et al. 2010. The dark side of light: a transdisciplinary research agenda for light pollution policy. Ecol Soc 15: 13

Kiyofuji H and Saitoh S-I. 2004. Use of nighttime visible images to detect Japanese common squid Todarodes pacificus fishing areas and potential migration routes in the Sea of Japan. Mar EcolProg Ser 276: 173-86.

Kyba CCM, Ruhtz T, Fischer J, and Hölker F. 2011. Cloud coverage acts as an amplifier for ecological light pollution in urban ecosystems. PLoS ONE 6: e17307.

Lessios HA. 1991. Presence and absence of monthly reproductive rhythms among eight Caribbean echinoids off the coast of Panama. J Exp Mar Biol Ecol 153: 27-47.

Longcore T and Rich C. 2004. Ecological light pollution. Front Ecol Environ 2: 191-98.

Marchesan M, Spoto M, Verginella L, and Ferrero EA. 2005. Behavioural effects of artificial light on fish species of commercial interest. Fish Res 73: 171-85.

Mäthger LM, Denton EJ, Marshall NJ, and Hanlon RT. 2009. Mechanisms and behavioural functions of structural coloration in cephalopods. J R Soc Interface 6: S149-63.

Mazor T, Levin N, Possingham HP, et al. 2013. Can satellite-based 
night lights be used for conservation? The case of nesting sea turtles in the Mediterranean. Biol Conserv 159: 63-72.

Merkel FR. 2010. Light-induced bird strikes on vessels in Southwest Greenland. Pinngortitaleriffik, Greenland: Greenland Institute of Natural Resources. Technical Report No 84.

MFSD (European Commission Marine Strategy Framework Directive). 2010. Commission decision on criteria and methodological standards on good environmental status of marine waters. Official Journal of the European Union. 2010/477/EU. L 232/14.

Moore MV, Pierce SM, Walsh HM, et al. 2000. Urban light pollution alters the diel vertical migration of Daphnia. Verhandlungen der IVL 27: 1-4.

Mundy CN and Babcock RC. 1998. Role of light intensity and spectral quality in coral settlement: implications for depthdependent settlement? J Exp Mar Biol Ecol 223: 235-55.

Naylor E. 1999. Marine animal behaviour in relation to lunar phase. Earth Moon Planets 85-86: 291-302.

Nordt A and Klenke R. 2013. Sleepless in town - drivers of the temporal shift in dawn song in urban European blackbirds. PLOS ONE 8: e71476.

Oppedal F, Dempster T, and Stien LH. 2011. Environmental drivers of Atlantic salmon behaviour in sea-cages: a review. Aquaculture 311: 1-18.

Rudd MA and Lawton RN. 2013. Scientists' prioritization of global coastal research questions. Mar Pol 39: 101-11.

Rydell J. 1992. Exploitation of insects around streetlamps by bats in Sweden. Funct Ecol 6: 744-50.

Secretariat of the Antarctic Treaty. 2010. Final report of the 33rd Antarctic Treaty Consultative Meeting. 3-14 May 2010; Punta del Este, Uruguay. Buenos Aires, Argentina: Secretariat of the Antarctic Treaty.
Siebeck UE, Parker AN, Sprenger D, et al. 2010. A species of reef fish that uses ultraviolet patterns for covert face recognition. Curr Biol 20: 407-10.

Small C and Nicholls RJ. 2003. A global analysis of human settlement in coastal zones. J Coastal Res 19: 584-99.

Stone EL, Jones G, and Harris S. 2012. Conserving energy at a cost to biodiversity? Impacts of LED lighting on bats. Glob Change Biol 18: 2458-65.

Sweeney AM, Boch CA, Johnsen S, and Morse DE. 2011. Twilight spectral dynamics and the coral reef invertebrate spawning response. J Exp Biol 214: 770-77.

Thorson G. 1964. Light as an ecological factor in the dispersal and settlement of larvae of marine bottom invertebrates. Ophelia 1 : 167-208.

Titulaer M, Spoelstra K, Lange CYMJG, and Visser ME. 2012. Activity patterns during food provisioning are affected by artificial light in free living great tits (Parus major). PLoS ONE 7: e37377.

Troscianko T, Benton CP, Lovell PG, et al. 2009. Camouflage and visual perception. Philos T R Soc B 364: 449-61.

Tuxbury SM and Salmon M. 2005. Competitive interactions between artificial lighting and natural cues during seafinding by hatchling marine turtles. Biol Conserv 121: 311-16.

Ugolini A, Boddi V, Mercatelli L, and Castellini C. 2005. Moon orientation in adult and young sandhoppers under artificial light. P Roy Soc B 272: 2189-94.

Vermeij MJA and Bak RPM. 2002. How are coral populations structured by light? Marine light regimes and the distribution of Madracis. Mar Ecol-Prog Ser 233: 105-16.

Yurk H and Trites AW. 2000. Experimental attempts to reduce predation by harbor seals on out-migrating juvenile salmonids. $T$ Am Fish Soc 129: 1360-66.

\section{NIED STA

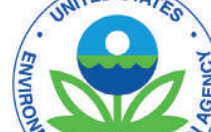 \\ U.S. Environmental Protection Agency Office of Research and Development National Exposure Research Laboratory \\ HIGH-LEVEL CAREER OPPORTUNITY Computational Exposure Scientist Announcement Number: RTP-ORD-42-2014-0004}

EPA's Office of Research and Development (ORD), National Exposure Research Laboratory (NERL), is seeking a highly recognized scientific leader to direct and conduct a cutting edge research program in the area of computational exposure science. The position will be located in Research Triangle Park, North Carolina.

NERL is leading the development of approaches to exposure science that take advantage of new advances in information and monitoring technology and large new sources of data to improve the rate and scope of exposure assessments. This new approach, "computational exposure science," integrates advances in informatics, chemistry, computer sciences, mathematics, statistics and social and behavioral sciences with new and numerically efficient models to more effectively predict real-world exposures.

\section{More information on ORD's NERL can be found at: WWW.PPa.gOV/nerl}

The incumbent will develop and implement complex computational solutions that facilitate the use of "big data" to develop an understanding of the factors that lead to exposure and to develop rapid exposure and dose exposure for chemicals.

In doing so, the incumbent will utilize knowledge of advanced informatics methods, tools and resources in chemistry, environmental science, exposure science, and behavioral science to interpret and understand the importance of various data sets relative to characterizing human and ecological exposure.

Salary and Benefits: This is a Title 42 authority appointment. The position is a full-time, renewable, 5 -year term appointment. Determination of salary is dependent upon qualifications, experience, and other factors (e.g., current salary, market salary rates). The selected applicant will be eligible for full benefits including relocation expenses, health and life insurance, retirement, and vacation and sick leave.

Applicants must be U.S. citizens or permanent residents. EPA is an Equal Opportunity Employer, and selection for this position will be based solely on merit without regard to race, color, religion, age, gender, national origin, political affiliation, disability, sexual orientation, marital or family status or any other non-merit factors.

Specific information on the position and instructions for applying can be found at: WWW_USajobs_gOV/

Applications must be received by 11:59 p.m. ET on August 15, 2014, in order to be considered.

Applications will not be considered if submitted via USAJOBS. 